\title{
Tourism and protected areas: A growing nexus of challenge and opportunity
}

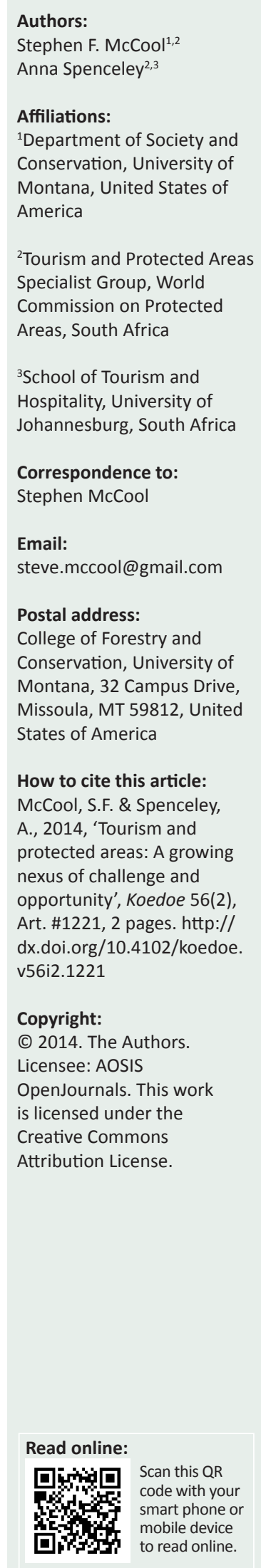

Three significant trends are converging with the result of increasing the importance of understanding and managing the nexus of tourism and protected areas. Firstly, international travel and tourism continues to grow significantly, resulting in more people wanting to visit, learn and appreciate their natural and cultural heritage. Secondly, international conservation efforts are increasingly dependent on protected areas serving as the cornerstone of slowing (ideally stopping) the loss of biological diversity. Thirdly, demands from society on protected areas are not only increasing, they are diversifying as well. Increased demand is, in part, the result of a growing human population that competes for space with natural areas and its wildlife through other land uses such as agriculture. Diversifying because protected areas are increasingly viewed as a source of monetary revenue and ecosystem-based benefits, such as health for humans, as engines of local livelihood development, as mechanisms for catalysing 'peace' on a transboundary scale and even as models of governance. These three trends accelerate the need for not only greater institutional capability to manage visitors and tourism development - which are amongst the most significant capacity needs, according to the World Commission on Protected Areas (2012) - but also more knowledge about visitor preferences, their behaviour, needs, spending patterns and social and environmental impacts. The convergence of these three trends also poses new challenges and opportunities not just for the conservation movement but for civil society as well.

At the World Parks Congress held in Durban, South Africa in 2003, participants recognised the need for increased research to strengthen the knowledge base essential for good management of visitors and tourism development. In the 11 years since the Congress, communities and conservation agencies have turned even more towards tourism as a means of enhancing the public understanding of natural heritage needed for political action that forms the basis for effective conservation. Tourism is also viewed as a source of at least some of the funding needed to manage a 'system' of parks and protected areas that encompass over $13 \%$ of the earth's terrestrial surface and $10 \%$ of the world's oceans (Bertzky et al. 2012). Tourism is a sector that can provide economic opportunities and enhance the quality of life for many citizens (both residents and tourists). Harnessing options for corporate social responsibility, volunteer tourism and value chain linkages within the sector, can also provide desperately needed access to health and education for poverty stricken residents living near protected areas.

As various nations move toward meeting the Aichi Targets (Secretariat to the Convention on Biological Diversity 2011) established by the Conference of the Parties to the Convention on Biological Diversity in 2011 (particularly Target 11, which identifies a goal of 17\% of the terrestrial surface of the earth to be protected within formally designated areas), we would expect many of these new areas to be in places already occupied or accessed by humans for shelter and sustenance. Gazetting protected areas comes with certain restrictions on access and resource use and thus revenues and economic opportunity from tourism will likely become an important argument in gaining local political support. In this context, activists, protected area managers, local entrepreneurs and development agencies will need an expanded knowledge base upon which to build successful tourism enterprises. Local communities will also need to be ready for influxes of people and to fabricate economic partnerships and alliances that not only protect heritage, but also provide opportunities for high quality visitor experiences.

These new capacities will need information, knowledge and wisdom. Information provides the descriptive base for what products a local area may hold of interest to visitors, what market segments may be available or of interest to tourism providers and what impacts, positive and negative, may come along with increased tourism activity. Knowledge helps us understand how things work, such as marketing (i.e. making connections between people and products), the effectiveness, equity and efficiency considerations of alternative benefit distribution mechanisms, as well as what factors affect relationships between tourism and impacts. Finally, 
managing tourism requires wisdom, the critical thinking that accompanies such questions as: what it is that tourism should sustain, what frameworks help us gain useful insights about managing a new local industry and how can partnerships form and continue in light of global level stresses and strains?

Research plays important roles in all these activities and thus is an essential element of any capacity-building effort. Scientists develop new knowledge, disseminate that knowledge through publication, professional presentations and participation in policy level dialogues and, in so doing, advance the practice. Strengthening research capacity helps build managerial capacity. Not only can it play an important role in building professional competencies to manage tourism, but it requires capacity-building efforts itself. One element of this capacity involves developing a cadre of scientists who are productive and doing work salient to the needs of the tourism industry - protected area managers, communities, tourism businesses and so on. This includes researchers who can take a multidisciplinary view and be cognisant of the complexity of the industry and its diverse political, institutional, environmental, social and economic challenges and opportunities. Another element that must become a focus centres on scientists being competent scientists, for example, being aware of contemporary methodologies, theories and conceptual frameworks, being engaged within a network of their peers and people living in tourism destinations, to build confidence and skills, creating a passion for conservation and interacting with practitioners to be mindful of, and responsive to, emerging issues and trends.

Owing to the sensitivity of the attractions involved, naturebased tourism is in need of particular attention by science. Therefore, this Special Issue of Koedoe was developed to encourage engagement by scientists in nature-based tourism and demonstrate that such science has relevancy to not just ensure protection of heritage, but also to local communities and to visitors. By better understanding relationships between visitor use and impact, we enhance managerial capacity to reduce such impacts and better match visitors and tourism development with resource capabilities. By developing knowledge about the experiences visitors seek and how they respond to the settings provided, we also build information about how opportunities for high quality - and therefore more competitive - visitor experiences can be built. By understanding visitor markets, we can construct more effective marketing campaigns which would lead to greater levels of per visitor spending locally, thus enhancing economic opportunity.

However, this requires an investment not just in capacitybuilding programmes but in science as well. As all knowledge is tentative, a continuing flow of research is needed to refresh our understanding and enhance our wisdom, both of which a fundamental to proficient management. This Special Issue of Koedoe, led by members of the International Union for Conservation of Nature (IUCN's) Tourism and Protected Areas Specialist Group, thus represents one examination of interaction between visitation, parks and communities. We believe it can play an important role in forming a knowledge base for further discussion and inquiry at the World Parks Congress in November 2014 in Sydney, Australia.

\section{References}

Bertzky, B., Corrigan, C., Kemsey, J., Kenney, S., Ravilious, C., Besançon, C. et al., 2012, Protected planet report 2012: Tracking progress towards global targets for protected areas, IUCN, Gland.

Secretariat to the Convention on Biological Diversity, 2011, COP 10 Decision X/2 strategic plan for biodiversity 2011-2020, viewed 18 January 2014, from http:// www.cbd.int/decision/cop/?id=12268

World Commission on Protected Areas, 2012, viewed 22 June 2012, http://www.iucn. org/about/union/commissions/wcpa/wcpa_what/wcpa_capacity/ 